\title{
Commentary: Structural valve degeneration in the era of precision medicine
}

\author{
Paul W. M. Fedak, MD, PhD, FRCSC ${ }^{a, b}$
}

\author{
From the a Section of Cardiac Surgery, Department of Cardiac Sciences, Cumming School of Medicine, Libin Car- \\ diovascular Institute of Alberta, University of Calgary, Calgary, Alberta, Canada; and ${ }^{\mathrm{b}}$ Bluhm Cardiovascular \\ Institute, Northwestern University, Chicago, Ill. \\ Disclosures: Author has nothing to disclose with regard to commercial support. \\ Received for publication Sept 20, 2018; accepted for publication Sept 21, 2018; available ahead of print Oct 30, \\ 2018. \\ Address for reprints: Paul W.M. Fedak, MD, PhD, FRCSC, C880, 1403-29 St NW, Calgary T2N 2T9, Alberta, \\ Canada (E-mail: paul.fedak@gmail.com). \\ J Thorac Cardiovasc Surg 2019;157:1391-2 \\ $0022-5223 / \$ 36.00$ \\ Copyright (C) 2018 by The American Association for Thoracic Surgery \\ https://doi.org/10.1016/j.jtcvs.2018.09.105
}

Aortic valve replacement (AVR) is a safe and routine technical procedure. Much more challenging is the preoperative decision for the type of prosthesis and optimal delivery platform. ${ }^{1}$ We must assess numerous options in the current era. There is a strong patient preference for a bioprosthesis despite the risk of structural valve degeneration (SVD). To provide optimal long-term outcomes and a durable solution, determining an individual's risk of SVD is critical to guide this decision-making process.

In this issue of the Journal, Senage and colleagues ${ }^{2}$ examined more than 500 patients who underwent surgical AVR with a Sorin Mitroflow bioprosthesis (Sorin Group, Arvada, Colo). The prosthesis was an early version without anticalcification treatments (model 12A/LX). ${ }^{3}$ Most of the patients were aged more than 70 years and had small roots given that the majority were implanted with size 19 or 21 . The Mitroflow has a design with bovine pericardium on the outside of the valve frame. It became a popular choice for surgeons dealing with smaller roots to minimize patient-prosthesis mismatch. The patient cohort in this series suggests a similar rationale for its use.

A higher than expected risk of SVD was previously documented in this series. ${ }^{4}$ The current study is unique in that it applies a modified statistical modeling methodology to improve the precision of the SVD estimate. The investigators hypothesized that SVD is underestimated using conventional statistical models. To improve precision, they applied an "interval-censored" process and analyzed SVD as defined by changes from serial echocardiograms after surgery. The actual risk of developing SVD was higher than previously calculated. Although numerous prior reports show increased SVD with this prosthesis, ${ }^{3}$ the new analysis supports that the revised model may indeed be more robust and could improve precision to evaluate the rate of SVD.

With further validation, there are compelling reasons to believe this new model should be widely adopted to explore

\section{References}

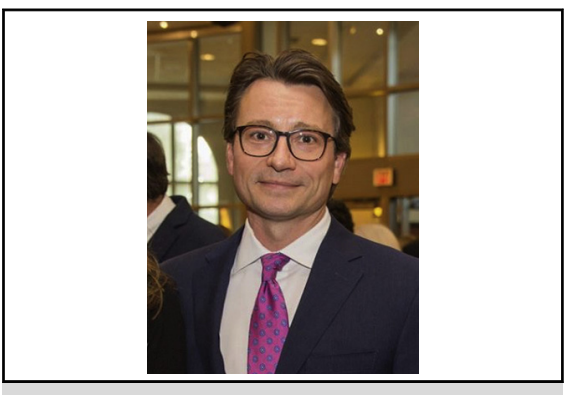

Paul W. M. Fedak, MD, PhD, FRCSC

Central Message

In an era of precision medicine, we must integrate the best available information to guide prosthesis selection.

See Article page 1383 .

SVD in studies going forward. Most studies show seemingly similar rates of SVD irrespective of the bioprosthesis type. More precision in our estimates may help distinguish which valves are truly better with respect to actual SVD risks. Some devices may be better suited to selected patients at higher risk of SVD. With increasing use of transcatheter AVR for patients with lower operative risk, it is imperative that we have precise estimates for SVD to best determine which delivery platform is best for which patient. Improvements in mechanical valve design can also safely reduce the level of anticoagulation, resulting in a reduced bleeding risk. ${ }^{5}$ We must have precise estimates of SVD for younger patients who may also be candidates for innovative new mechanical valves that have the potential to improve survival. ${ }^{6}$

A new approach to more precisely determine the risk of SVD has been proposed. The proposed model may improve estimation of SVD and, in so doing, help us identify additional individual clinical factors that may influence valve selection. In an era of precision medicine, we must integrate the best available information to guide prosthesis selection.

1. Fedak PWM, Bhatt DL, Verma S. Aortic valve replacement in an era of rapid innovation: better the devil you know. J Am Coll Cardiol. 2018;71:1413-6.

2. Sénage T, Gillaizeau F, LeTourneau T, Marie B, Roussel JC, Foucher Y. Structural valve deterioration of bioprosthetic aortic valve: an underestimated complication. J Thorac Cardiovasc Surg. 2019;157:1383-90.e5.

3. Balsam LB, DeAnda A Jr. The Mitroflow aortic valve: a past, present, and future illuminated. J Thorac Cardiovasc Surg. 2017;153:40-2.

4. Sénage T, Le Tourneau T, Foucher Y, Pattier S, Cueff C, Michel M, et al. Early structural valve deterioration of Mitroflow aortic bioprosthesis: mode, incidence, 
and impact on outcome in a large cohort of patients. Circulation. 2014;130: 2012-20.

5. Puskas J, Gerdisch M, Nichols D, Quinn R, Anderson C, Rhenman B, et al Reduced anticoagulation after mechanical aortic valve replacement: interim results from the prospective randomized on- $\mathrm{X}$ valve anticoagulation clinical trial randomized Food and Drug Administration investigational device exemption trial J Thorac Cardiovasc Surg. 2014;147:1202-11.

6. Goldstone AB, Chiu P, Baiocchi M, Lingala B, Patrick WL, Fischbein MP, et al Mechanical or biologic prostheses for aortic-valve and mitral-valve replacement. N Engl J Med. 2017;377:1847-57. 